\title{
Optimal location and reactive power injection of wind farms and SVC's units using voltage indices and PSO
}

\author{
Nazha Cherkaoui, Abdelaziz Belfqih, Faissal El Mariami, Jamal Boukherouaa, Abdelmajid Berdai
}

Laboratory of Electrical Systems and Energy, National Higher School of Electricity and Mechanics (ENSEM), Morocco

\begin{tabular}{l}
\hline \hline Article Info \\
\hline Article history: \\
Received Oct 19, 2018 \\
Revised Apr 5, 2019 \\
Accepted Apr 15, 2019 \\
\hline
\end{tabular}

\section{Keywords:}

Active power losses

Optimization method

PSO

SVC

Voltage profile

Wind power plants

\begin{abstract}
Nowadays, the use of the wind energy has known an important increase because it is clean and cheap. However, many technical issues could occur due to the integration of wind power plants into power grids. As a result, many countries have published grid code requirements that new installed wind turbines (WT) have to satisfy in order to facilitate its intergration to electrical networks. Among those requirements, the wind farms must be able to participate to ancillary services for instance voltage regulation and reactive power control. Nevertheless, in case of small wind farms having not the necessary reactive power capability to contribute to reactive power support, Flexible AC Transmission Systems (FACTS) devices could also be used to participate to reactive power support. In this paper, an optimization method based on particle swarm optimization (PSO) technique is presented. This method allows getting the optimal location and reactive power injection of both wind power plants (WPP) and synchronous var compensators (SVC) with the objective to improve the voltage profile and to minimize the active power losses. The IEEE 14 bus system and a $20 \mathrm{MW}$ wind farm based doubly fed induction generator (DFIG) are used to validate the proposed algorithm. The simulation results are analysed and compared.
\end{abstract}

Copyright () 2019 Institute of Advanced Engineering and Science. All rights reserved.

\section{Corresponding Author:}

Nazha Cherkaoui,

Laboratory of Electrical Systems and Energy,

National Higher School of Electricity and Mechanics,

El Jadida Road, Km 7, Casablanca, Morocco.

Email: nazha.cherkaoui@ensem.ac.ma

\section{INTRODUCTION}

Recently, the penetration of the wind farms into electrical grids have known a significant growth. According to [1], the global installed wind power in the world reached 539,581 GW in 2017. Nevertheless, the important increase of the wind power plants (WPP) integration into power systems could cause many technical issues, for instance: voltage fluctuations, voltage variations and harmonics [2]. Therefore, in order to ensure a reliable grid operation with the important growth of electricity production from renewable sources, transmission system operators (TSO) should use appropriate operating strategies. Reactive power management is an important part of power systems plans because the stability and the reliability of electrical networks depend on it. If an optimum location of VAR sources are chosen during the planning stage, an effective reactive power planning could be obtained; also, when an optimum regulation of the VAR setting is scheduled during the reactive power dispatch, an effective reactive power dispatch could be obtained [3]. Besides, FACTS devices can be used to improve the voltage stability. An optimal allocation of FACTS devices taking into account location and size is the key of reactive power planning [4].

In literature, many works have been done in order to find the optimal location and size of FACTS devices by using several optimisation techniques with the aim to improve voltage profile. In fact, in [5], the authors present a new method to find the optimal number, location and size of SVC using voltage indices and PSO algorithm to improve voltage stability. In addition, authors in [6] use the harmony search algorithm 
(HAS) to determine the optimal location and setting of SVC and TCSC (thyristor controlled series capacitor) respectively with the aim to minimize the bus voltage deviation and real power losses. In other works, diverse methods have been proposed in order to find the optimal location and reactive power injection of wind farms or wind turbines with the purpose to guarantee certain objectives. For instance, in [7], the authors present a method that allows obtaining the optimal placement and sizing of wind power generators in power grids with the purpose to reduce reactive power losses and coping maximum loadability margin. Also, Singh et al. [8] presents an approach that permits getting the optimum value of reactive power output by a wind farm with the objective to minimize power losses and to improve voltage profile by using genetic algorithm. Besides, the authors in [9] discuss an optimization problem in which the goal is to find the optimal placement and sizing of wind turbines in the electrical network in order to minimize the active power losses, and to maximize the system loadbility within security margin.

However, in case of installing small wind farms into power grids having not sufficient reactive power capability in order to contribute to reactive power support, it will be benefit to use an optimization method in order to find the optimal placement and reactive power injection of both wind farms and FACTS devices. In this work, we propose an objective function that allows getting the optimal number of SVC to install in the grid. The objective function presented in this paper aims also to find the optimal location and reactive power injection of both the SVC's units and the wind farm with the target to reduce power losses and to enhance voltage stability.

This work is organized as follows: first, the method used in order to get the reactive power capability of the wind farm made up with DFIG wind turbine is presented. Second, the voltage stability indices and the PSO algorithm used in this work are presented followed by the formulation of the objective function for optimal placement and reactive power injection of the WF and the SVC's units. Finally, the case study and the simulation results are reported.

\section{REACTIVE POWER CAPABILTY OF THE WIND FARM BASED DFIG WIND TURBINE}

In this paper, we use the DFIG wind turbine because it is the technology the most installed in wind farms for its several advantages. For instance, with the DFIG technology, it is possible to get the required reactive power at the stator side by controlling the rotor currents by the rotor side converter [10].

The method proposed in [11] is used to get the reactive power capability of the DFIG based wind turbine $\mathrm{Q}_{\mathrm{WT}}^{\max }$ and $\mathrm{Q}_{\mathrm{WT}}^{\min }$. In this method, it is suggested that the reactive power capability is bounded by three parameters: rotor voltage $V_{r}$, rotor $I_{r}$ and stator currents $I_{s}$. The parameters cited in [12] are used to get the PQ diagram of $2 \mathrm{MW}$ DFIG wind turbine used in this work. For more details, refer to [13]. In this work, the reactive power losses are neglected within the wind farm, so the reactive power capability of the WPP $\left(Q_{W F}^{\max }\right.$ and $\mathrm{Q}_{\mathrm{WF}}^{\min }$ ) is calculated as below:

$$
\begin{aligned}
& \mathrm{Q}_{\mathrm{WF}}^{\max }=\sum \mathrm{Q}_{\mathrm{WT}}^{\max } \\
& \mathrm{Q}_{\mathrm{WF}}^{\min }=\sum \mathrm{Q}_{\mathrm{WT}}^{\min }
\end{aligned}
$$

\section{LINE VOLTAGE STABILITY INDICES $[14,15]$}

In this work, the voltage stability indices $\mathrm{L}_{\mathrm{mn}}, \mathrm{L}_{\mathrm{QP}}$ and FVSI are used. These indices are formulated based on power transmission in a single line as illustrated in Figure 1. A transmission line is stable as long as the values of these indices remain below 1. If the value of one of them exceeds 1, the system loses its stability and the voltage collapses [15]. These indices are obtained as follows:

$$
\begin{aligned}
& \mathrm{L}_{\mathrm{mn}}=\frac{4 \mathrm{X} \mathrm{Q}_{\mathrm{r}}}{\left(\mathrm{V}_{\mathrm{s}} \sin (\theta-\delta)\right)^{2}} \\
& \mathrm{~L}_{\mathrm{QP}}=4\left(\frac{\mathrm{X}}{\mathrm{V}_{\mathrm{s}}^{2}}\right)\left(\mathrm{Q}_{\mathrm{s}}+\frac{\mathrm{P}_{\mathrm{S}}^{2} \mathrm{X}}{\mathrm{V}_{\mathrm{s}}^{2}}\right) \\
& \mathrm{FVSI}=\frac{4 \mathrm{Z}^{2} \mathrm{Q}_{\mathrm{r}}}{\mathrm{V}_{\mathrm{s}}^{2} \mathrm{X}}
\end{aligned}
$$

where

$\mathrm{X} \quad$ : line reactance.

Qr : reactive power at the receiving bus. 
Vs : voltage magnitude at the sending bus.

$\theta \quad$ : line impedance angle.

$\delta \quad: \quad$ : the angle difference between the voltage angle at the sending and receiving bus.

Qs : reactive power at the sending bus.

Ps : active power at the sending bus.

$\mathrm{Z} \quad$ : the line impedance amplitude.

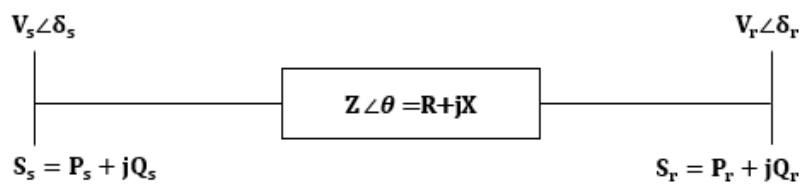

Figure 1. One line diagram of transmission line

\section{PARTICLE SWARM OPTIMISATION TECHNOQUE (PSO)}

The particle swarm optimisation (PSO) technique is a metaheuristic algorithm invented by Kennedy and Eberhart in 1995 [16]. This optimisation method aims to find the parameters that give the minimum (or maximum) of an objective function [17]. We opt to use the PSO algorithm in this work due to the fact that it converges more to the optimal solution with less overhead of parameter setting and less computation time in comparaison with other metaheuristic methods [18].

In the PSO method, a group of particles are initialized in a random manner in the d-dimensional search space, where $d$ is the number of the decision variables in the optimisation problem. A position vector $\mathrm{x}_{\mathrm{i}}$, a velocity vector $\mathrm{v}_{\mathrm{i}}$ and a position Pbest $_{\mathrm{i}}$ are associated to each $\mathrm{i}$-th particle. In order to find the optimal solution, the particles exchange effectively information during an iterative process. In each iteration, the best global position gbest found by any particle in the swarm is shared with all the rest of the particles. In each $\mathrm{k}$-th iteration, the velocity and the position are updated using the equations below [19]:

$$
\begin{aligned}
& v_{i}^{k+1}=w^{k} v_{i}^{k}+c_{1} r_{1}\left(\text { Pbest }_{i}^{k}-x_{i}^{k}\right)+c_{2} r_{2}\left(\text { gbest }^{k}-x_{i}^{k}\right) \\
& x_{i}^{k+1}=x_{i}^{k}+v_{i}^{k+1}
\end{aligned}
$$

where

$r_{1}$ and $r_{2}$ : uniformly distributed random numbers in the range [0 1].

w : inertia weight.

$\mathrm{c}_{1}$ and $\mathrm{c}_{2}$ : acceleration coefficients.

There are several inertia weighting factors, in this paper, we use the following one [19]:

$$
\mathrm{w}^{\mathrm{k}}=\mathrm{w}_{\max }-\frac{\mathrm{w}_{\max }-\mathrm{w}_{\min }}{\mathrm{k}_{\max }} \mathrm{xk}
$$

where

$\mathrm{k}_{\max } \quad:$ the maximum number of iterations.

$\mathrm{k} \quad$ : the current number of iterations.

$\mathrm{w}_{\min }$ and $\mathrm{w}_{\mathrm{wax}}:$ are the lower and the upper bounds of the inertia weighting factors, respectively.

\section{PROBLEM FORMULATION}

The purpose of the objective function proposed in this work is to find the optimal number $\mathrm{n}_{\mathrm{svc}}$ of SVC to install in the network. In addition to that, the objective function aims to find the optimal location and the reactive power injection of both a wind farm based DFIG WT and the number $\mathrm{n}_{\mathrm{svc}}$ of SVC. The found parameters reduce the power losses and enhance the voltage stability in the grid. The objective function to minimize in this work is represented as:

$$
\mathrm{F}(\mathrm{X})=\lambda_{1} \cdot \mathrm{P}_{\text {losses }}+\lambda_{2} \cdot \sum_{\mathrm{i}=1}^{\mathrm{N}_{\text {lines }}} \frac{\mathrm{L}_{\mathrm{QP}}(\mathrm{i})+\mathrm{L}_{\mathrm{mn}}(\mathrm{i})+\mathrm{FVSI}(\mathrm{i})}{3}
$$


where

$\mathrm{P}_{\text {losses }} \quad$ : power losses in the electrical grid. In this work, we neglect the power losses in the

wind farm.

$\mathrm{N}_{\text {lines }} \quad:$ the number of lines in the grid.

$\mathrm{L}_{\mathrm{QP}}, \mathrm{L}_{\mathrm{mn}}$ and FVSI : voltage stability indices.

$\mathrm{X}=\left(\mathrm{X}_{1}, \mathrm{X}_{2}, \mathrm{x}_{3}, \mathrm{X}_{4}, \mathrm{X}_{5}, \mathrm{X}_{6}, \mathrm{X}_{7}\right):$ : the position of each particle.

$\lambda_{1}, \lambda_{2} \quad$ : weight coefficients

with

$$
\mathrm{L}_{\mathrm{WF}}=\mathrm{x}_{1}, \mathrm{Q}_{\mathrm{WF}}=\mathrm{x}_{2}, \mathrm{n}_{\mathrm{SVC}}=\mathrm{x}_{3}, \mathrm{~L}_{\mathrm{SVC} 1}=\mathrm{x}_{4}, \mathrm{~L}_{\mathrm{SVC} 2}=\mathrm{x}_{5}, \mathrm{Q}_{\mathrm{SVC} 1}=\mathrm{x}_{6}, \mathrm{Q}_{\mathrm{SVC} 2}=\mathrm{x}_{7}
$$

LWF : optimal location of the wind farm

$\mathrm{Q}_{\mathrm{WF}} \quad$ : reactive power to produce or to absorb by the wind farm

$\mathrm{L}_{\mathrm{SVCi}} \quad$ : optimal location of the SVC (load buses in the grid)

$\mathrm{Q}_{\mathrm{SVCi}} \quad$ : reactive power to inject by the SVC. In this work, the SVC is considered as a variable load.

$\mathrm{n}_{\mathrm{SVC}} \quad$ : optimal number of the SVC to be installed in the network, with $0 \leq \mathrm{nsvc} \leq 2$

If $\mathrm{n}_{\mathrm{SVC}}=0$ then $\mathrm{L}_{\mathrm{SVC} 1}=0, \mathrm{~L}_{\mathrm{SVC} 2}=0, \mathrm{Q}_{\mathrm{SVC} 1}=0$ and $\mathrm{Q}_{\mathrm{SVC} 2}=0$

If $\mathrm{n}_{\mathrm{SVC}}=1$ then $\mathrm{L}_{\mathrm{SVC} 2}=0$ and $\mathrm{Q}_{\mathrm{SVC} 2}=0$

The objective function proposed in this work is subject to the following constraints:

1) Wind farm reactive power limits

$$
\mathrm{Q}_{\mathrm{wf}}^{\min } \leq \mathrm{Q}_{\mathrm{wf}} \leq \mathrm{Q}_{\mathrm{wf}}^{\max }
$$

2) Number of SVC $n_{S V C}$

$$
0 \leq \mathrm{nsvc} \leq 2
$$

3) SVC reactive power capacity

$$
\mathrm{Q}_{\mathrm{svc}}^{\min } \leq \mathrm{Q}_{\mathrm{svc}} \leq \mathrm{Q}_{\mathrm{svc}}^{\max }
$$

In this work, the operating range of the SVC is considered to be $\pm 50 \mathrm{MVAR}$

First, the position of the PSO algorithm is initialized randomly with possible values in the space $[N 1, N 2, \ldots N P Q]$ (load buses placed in the electrical grid), $\left[Q_{W F}^{\min }, Q_{W F}^{\max }\right],[0,1,2],[N 1, N 2, \ldots, N P Q]$, $\left[Q_{\mathrm{svc}}^{\min }, Q_{\mathrm{svc}}^{\max }\right]$. Then, at each iteration, as illustrated in Figure 2, the proposed algorithm looks for the optimal solution by updating the position and the velocity of each i-th particle taking into account its previous best position Pbesti and the best position of the group gbest.

\section{SIMULATION RESULTS}

In order to validate the proposed optimisation algorithm, three different cases are simulated using a wind farm constituted of ten 2 MW DFIG based wind turbine and the IEEE 14 bus system. We consider that the wind turbines within the WPP operate at full active power and we neglect the power losses within the wind farm. The active loads in buses 9 and 13 are increased to $245 \mathrm{MW}$ and 67,5 MW, respectively. Consequently, the voltage amplitudes in buses 4, 5, 9, 10 and 14 decrease significantly.

- Case 1: without the wind farm or the SVC.

- Case 2: only with the wind farm.

where

$\mathrm{X}=\left(\mathrm{x}_{1}, \mathrm{x}_{2}\right), \mathrm{L}_{\mathrm{WF}}=\mathrm{x}_{1}$ and $\mathrm{Q}_{\mathrm{WF}}=\mathrm{x}_{2}$

$\lambda_{1}=\lambda_{2}=0,5$

- Case 3: with both the wind farm and the SVC's units.

where

$\mathrm{X}=\left(\mathrm{x}_{1}, \mathrm{x}_{2}, \mathrm{x}_{3}, \mathrm{x}_{4}, \mathrm{x}_{5}, \mathrm{x}_{6}, \mathrm{x}_{7}\right), \mathrm{L}_{\mathrm{WF}}=\mathrm{x}_{1}, \mathrm{Q}_{\mathrm{WF}}=\mathrm{x}_{2}, \mathrm{n}_{\mathrm{SVC}}=\mathrm{x}_{3}, \mathrm{~L}_{\mathrm{SVC} 1}=\mathrm{x}_{4}, \mathrm{~L}_{\mathrm{SVC} 2}=\mathrm{x}_{5}, \mathrm{Q}_{\mathrm{SVC} 1}=\mathrm{x}_{6}, \mathrm{Q}_{\mathrm{SVC} 2}=\mathrm{x}_{7}$ $\lambda_{1}=\lambda_{2}=0,5$ 


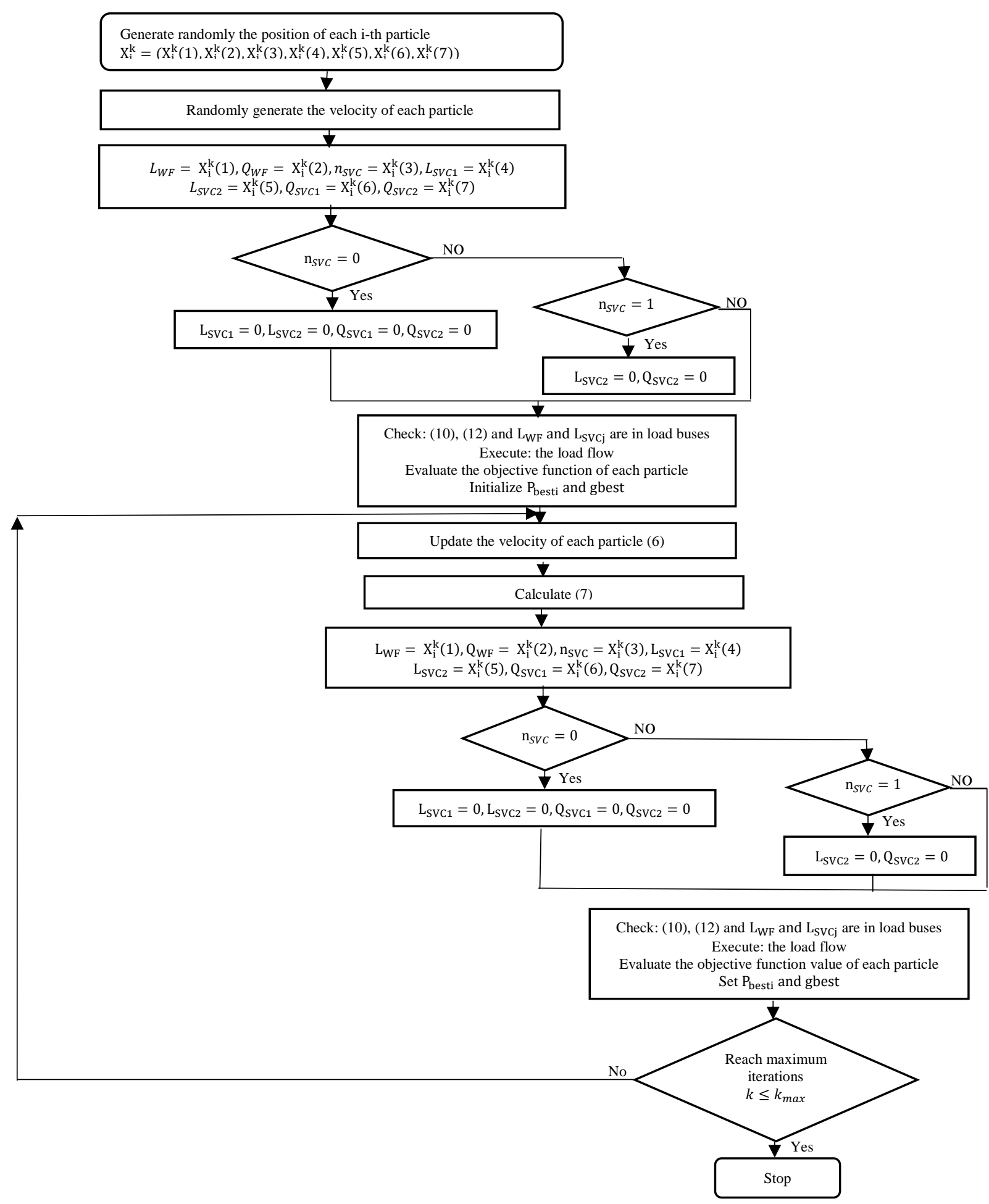

Figure 2. Flow chart of the proposed algorithm

The results obtained in the three cases are presented in Table 1. In case 3, as shown in Table 1, the optimal location of the wind farm is bus number 9, and the optimal location of the two SVC are buses number 9 and 5 . 
Table 1. Simulation results

\begin{tabular}{lccc}
\hline & Case 1 & Case 2 & Case 3 \\
\hline $\mathbf{L}_{\mathbf{W F}}$ & - & 9 & 9 \\
$\mathbf{Q}_{\mathbf{W F}}$ (MVAR) & - & 6,2779 & 6,2779 \\
$\mathbf{n}_{\mathbf{S V C}}$ & - & - & 2 \\
$\mathbf{L}_{\mathbf{S V C 1}}$ & - & - & 9 \\
$\mathbf{L}_{\mathbf{S V} 2}$ & - & - & 5 \\
$\mathbf{Q}_{\mathbf{S V 1}}$ (MVAR) & - & - & 50 \\
$\mathbf{Q}_{\mathbf{S V} 2}$ (MVAR) & - & - & 50 \\
Objective function & - & 38,2254 & 36,0300 \\
\hline
\end{tabular}

As illustrated in Figure 3, the voltage amplitudes at buses 4, 5, 9, 10 and 14 increase respectively from 0,925 p.u, 0,935 p.u, 0,936 p.u, 0,948 p.u and 0,944 p.u. in the first case to 0,938 p.u, 0,947 p.u, 0,963 p.u, 0,971 p.u. and 0,962 p.u. in the second case. However, the significant improvement of the voltage is obtained in the third case. In fact, the voltage magnitudes in case 3 at buses 4, 5, 9, 10 and 14 are 0,964 p.u, 0.978 p.u, 1,031 p.u, 1,027 p.u. and 1,005 p.u., respectively. This is due to the fact that the reactive power injected in the grid in case 3 is bigger than that injected in case 2, as illustrated in Table 1. As shown in Figure 4 , the power losses are important in the first case and decrease significantly in the third case by $16,41 \%$ in comparison with the first case.

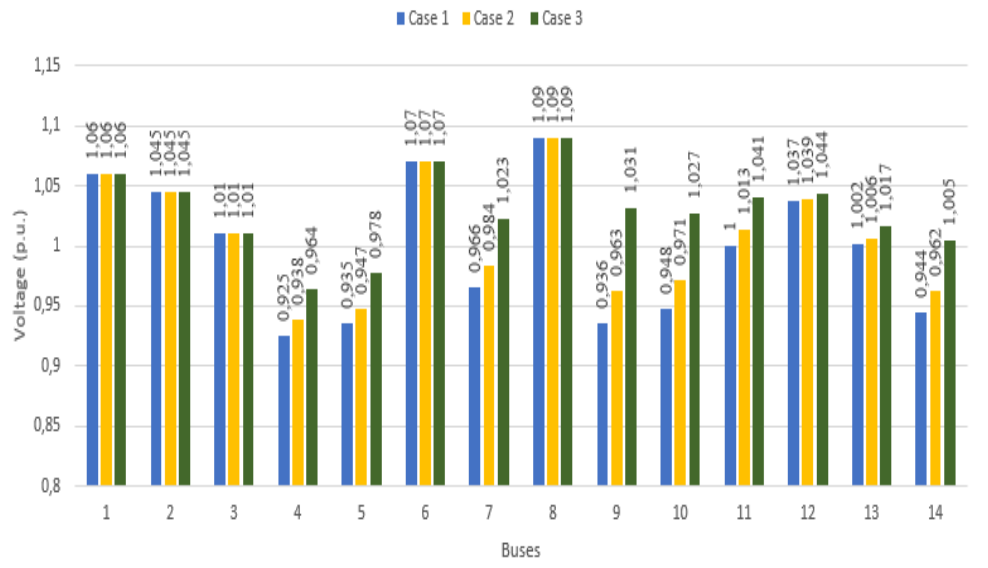

Figure 3.Voltage profile

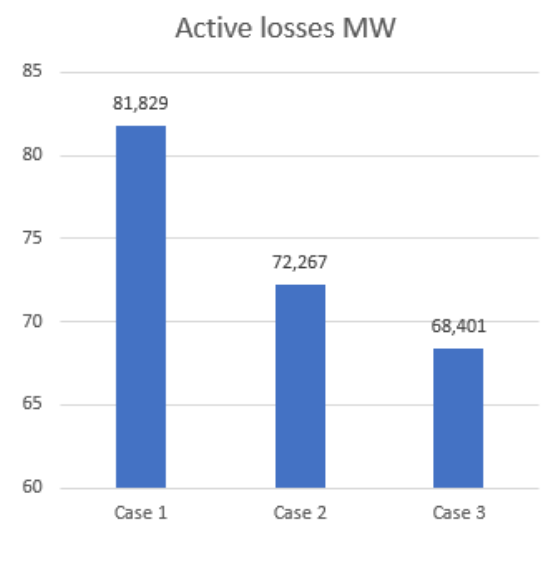

Figure 4. Power losses

According to the results obtained in case 2, looking only for the optimal placement and reactive power injection of a small wind farm in order to improve the voltage profile is not enough because it doesn't have sufficient reactive power capability to participate to reactive power support. Hence, in case of installing small wind farms into power grids, it will be beneficial to add SVC's units to the network. The optimization method proposed in this study aims to determine the optimal number of SVC's units to install in the grid in addition to small wind farms; also, it aims to find the optimal location and reactive power injection of the wind farm and ths SVC's units with the goal to minimize the power losses and to improve the voltage profile. In fact, using the proposed optimization method in case 3 allows getting the best results.

\section{CONCLUSION}

In this work, an optimisation algorithm based on particle swarm optimisation method (PSO) is presented. The proposed algorithm permits getting the optimal location and reactive power injection of both a wind farm and synchronous var compensators (SVC). The aim of the proposed algorithm is to enhance the voltage profile and to reduce the active power losses. The simulation results illustrate the effectiveness of the proposed method. 


\section{REFERENCES}

[1] "Global wind statistics 2017," Feb 2018. Available at www.gwec.net.

[2] Z. Chen, "Issues of connecting wind farms into power system," IEEE/PES Transmission and Distribution Conference \& Exhibition: Asia and Pacific, China, 2005.

[3] H. Amaris and M. Alonso, "Coordinated reactive power management in power networks with wind turbines and FACTS devices," Energy Conversion and Management, vol. 52, pp. 2575-2586, 2011.

[4] K. R. Vadivelu, "Multi objective optimal reactive power planning using improved differential evolution algorithm in power systems," Thesis, Sri Venkateswara University, Tirupati, India. Shodhganga, 2015. Available: http://shodhganga.inflibnet.ac.in/handle/10603/171783.

[5] M. N. Dazahra, et al., "Optimal Location of SVC using Particle Swarm Optimization and Voltage Stability Indexes," International Journal of Electrical and Computer Engineering (IJECE), vol/issue: 6(6), pp. 2581-2588, Dec 2016.

[6] D. Karthikaikannan and G. Ravi, "Optimal location and setting of FACTS devices for reactive power compensation using harmony search algorithm," AUTOMATIKA, vol. 52, pp. 881-892, 2016.

[7] S. Makhloufi, et al., "Cuckoo Search Algorithm for Integration Wind Power Generation to Meet Load Demand Growth," International Conference on Environment and Electrical Engineering, Milan, Italy, 2017.

[8] S. Singh, et al., "A Novel Approach for Reactive Power Output Optimization in Wind Farm for the Reduction of Distribution Losses using Genetic Algorithm," International Journal of Advanced Research in Electrical, Electronics and Instrumentation Engineering, vol/issue: 2(3), Mar 2013.

[9] I. M. Wartana, et al., "Optimal Integration of the Renewable Energy to the Grid by Considering Small Signal Stability Constraint," International Journal of Electrical and Computer Engineering (IJECE), vol/issue: 7(5), pp. 2329-2337, Oct 2017.

[10] P. Vijayan, "Utilizing reactive capability of doubly fed induction generators to enhance system voltage performance and withstand wind variability," master thesis, 2010.

[11] T. Lund, et al., "Reactive power capability of a wind turbine with doubly fed induction generator," Wind Energy, vol. 10, pp. 379-394, Apr 2007.

[12] A. Ahmidi, "Wind farms participation at voltage and reactive power regulation in the power system network," Phd dissertation, 2010.

[13] N. Cherkaoui, et al., "Voltage regulation in the electrical network using reactive power control strategy of WPP based DFIG wind turbine," 3rd Irnternational Conference on Electrical and Information Technologies ICEIT'2017, Rabat, Morocco, Nov 2017.

[14] H. H. Goh, et al., "Comparative study of line voltage stability indices for voltage collapse forecasting in power transmission system," World Academy of Science, Engineering and Technology, International Journal of Civil and Environmental Engineering, vol/issue: 9(2), 2015.

[15] J. Modarresi, et al., "A comprehensive review of the voltage stability indices," elsevier Renewable and Sustainable Energy Reviews, vol. 63, pp. 1-12, 2016.

[16] A. Erskine, et al., "Stochastic stability of particle swarm optimisation," Swarm Intelligence, vol. 11, pp. 295-315, 2017.

[17] J. Blondin, "Particle swarm optimization, applications of parameterization of classifiers," 2009. Available: www.cs.armstrong.edu/saad.

[18] L. A. Bewoor, et al., "Comparative Analysis of Metaheuristic Approaches for Makespan Minimization for No Wait Flow Shop Scheduling Problem," International Journal of Electrical and Computer Engineering (IJECE), vol/issue: 7(1), pp. 417-423, Feb 2017.

[19] T. Krzeszowski and K. Wiktorowicz, "Evaluation of selected fuzzy particle swarm optimization algorithms," Proceedings of the Federated Conference on Computer Science and Information Systems, vol. 8, pp. 571-575, 2016.

\section{BIOGRAPHIES OF AUTHORS}

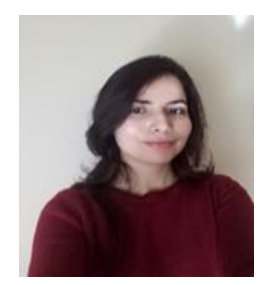

Nazha Cherkaoui is a Ph.D. student at the National Higher School of Electricity and Mechanics (University Hassan II of Casablanca - Morocco). Her research interests include renewable energies and power systemes.

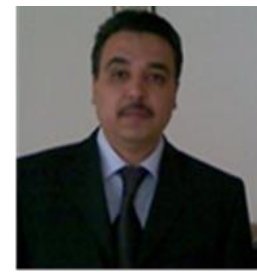

Abdelaziz Belfqih is a professor at the National Higher School of Electricity and Mechanics (University Hassan II of Casablanca - Morocco). PhD, Engineer and holder of the University Habilitation searches (HDR). Member of the research team "Electrical Networks and Static Converters". Teacher researcher currently working on electricity network and smart grids. 

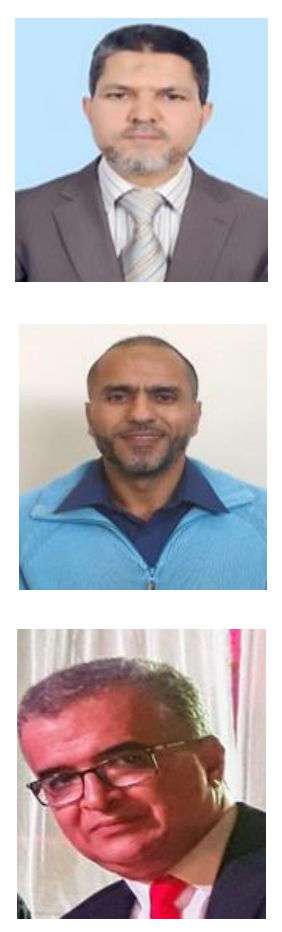

Faissal El Mariami is a professor at the Superior National Higher School of Electricity and Mechanics (University Hassan II of Casablanca - Morocco). PhD, Engineer and holder of the University Habilitation searches (HDR). Member of the research team "Electrical Networks and Static Converters". Teacher researcher currently working on stability of the electricity network and smart grids.

Jamal Boukherouaa is a professor at the National Higher School of Electricity and Mechanics (University Hassan II of Casablanca Morocco). PhD, Engineer and holder of the University Habilitation searches (HDR). Member of the research team "Electrical Networks and Static Converters". Teacher researcher currently working on high frequency static converters.

Abdelmajid Berdai holds a doctorate in engineering. He is currently Associate Professor and Chair of the Department of electrical engineering in the National School of Electricity and Mechanics (University Hassan II of Casablanca Morocco). Member of the research team "Electrical Networks and Static Converters". His research interests include Dynamic Simulation of Electric Machinery, Simulation and optimization of renewable energy systems, the use of quality power conversion for monitoring of electromechanical equipment state, Estimation of modes and diagnosis of induction motors based on the quality of energy conversion 